\title{
Assessment of Technology acceptance in Intensive Care Units
}

\author{
Filipe Portela ${ }^{1}$, Jorge Aguiar ${ }^{1}$, Manuel Filipe Santos ${ }^{1}$, António Abelha ${ }^{2}$, José Machado ${ }^{2}$, Álvaro \\ Silva ${ }^{3}$, Fernando Rua ${ }^{3}$, \\ ${ }^{1}$ Algoritmi Centre, University of Minho, Guimarães, Portugal \\ ${ }^{2}$ CCT, University of Minho, Braga, Portugal \\ ${ }^{3}$ Intensive Care Unit, Centro Hospitalar do Porto, Portugal \\ 1'cfp@dsi.uminho.pt, jorge.phena@gmail.com,mfs@dsi.uminho.pt \\ 2abelha@di.uminho.pt,jmac@di.uminho.pt \\ ${ }^{3}$ moreirasilva@clix.pt, fernandorua.sci@hgsa.min-saude.pt
}

\begin{abstract}
The process of deploy a technology in critical services need to be very careful planned and processed. As an example it is the Intensive Care Unit (ICU). In the ICU the patients are in critically ill conditions and there aren't available time to make experiences or to develop incomplete systems. With the objective to improve the implementation process, the same should be accompanied in order to understand the environment and user behaviour. In this case and with the goal to evaluate the implementation process, an assessment model was applied to a real system called INTCare.

INTCare is a Pervasive Intelligent Decision Support System (PIDSS). It was deployed in the ICU of Centro Hospitalar do Porto and was evaluated using the Technology Acceptance Model 3 (TAM). This assessment was made using the four constructs proposed by the TAM and a questionnaire-based approach guided by the Delphi Methodology. The results obtained so far show that although the users are satisfied with the offered information recognizing this importance, they demand for a faster system. This work present the main results achieved and suggest one way to follow when some technology is deployed in an environment like is ICU.
\end{abstract}

Keywords: TAM, INTCare, Technology Acceptance, Intensive Care, Decision Support System, Pervasive, Technology Assessment

\section{INTRODUCTION}

In the Intensive Care Units (ICU), the introduction of technologies can contribute to improve the Decision Making Process (DMP). As referred, ICU is recognized as a critical environment where the decision needs to be performed quickly and with a high level of accuracy. In the ICU it is applied a set of specific treatments related with a particular area of Medicine, called Intensive Medicine. Daily the ICU professionals are concerned with the patient care, being the patient documentation relegated to a second plane (Mador \& Shaw, 2009). The DMP in Intensive Medicine (IM) is a critical process because it deals with human lives in serious liferisk conditions. In the ICU nothing can fail and if something wrong happens the result can be catastrophic and result in a loss of a human life. IM is a specific area of Medicine. Their knowledge is practiced in the ICU (Baggs et al., 2007). The introduction of intelligent decision support systems (IDSS) in the support of the DMP it is claimed by many of the nurses and physicians which work in ICU. The system should be available anywhere and anytime, operating automatic and in real-time. One of the main objective of this type of systems is decreasing the time of documentation tasks made by the humans. Although it also should contribute to give a better comprehension about the patient condition and at the same time predict future situations. In the ICU of Centro Hospitalar do Porto a set of experiences were made and a pervasive IDSS (PIDSS) developed, namely INTCare. 
INTCare is a system developed by this research team and has as first goal to predict the patient organ failure and patient outcome in real-time for the next 24 hours. When the project started the most difficult aspect to overcome was the inexistence of electronic data. Most of the patient information were available only in the paper. This situation led the research team to deploy a platform which can help the ICU team in the documentation process. It was introduced a pervasive platform called: Electronic Nursing Record (ENR). ENR can monitoring all the patient clinical variables.

With the development of the main project, other types of data sources were deepened and as result some new knowledge were obtained. Currently, INTCare it is considered by the ICU staff a very useful and complete platform, being composed by a set of pertinent information to the Decision Making Process (DMP). To this work a list of requirements was defined based on the needs of ICU and with the goal to make the system more suitable to the environment. They may be summarized as:

R1. To implement an online data acquisition component;

R2. To make available the laboratory results in an open format;

R3. To allow an open access to prescriptions, interventions and therapeutics;

R4. To dematerialise the nursing records;

R5. To integrate the main systems used in ICU in a single platform;

R6. Develop an automatic system to process and transforming the data.

Taking advantage of the modifications introduced (R1 to R6) it is possible to determine automatically and in real-time, using online learning:

- ICU Medical Scores (Portela et al., 2012);

- ICU Critical Events (P. G. Filipe Portela, Manuel Filipe Santos, Álvaro Silva, Fernando Rua, 2012);

- Probability of occur an organ failure probability and patient die (F. P. Filipe Portela, Manuel Filipe Santos, 2012).

In order to assess the technology developed, the Technology Acceptance Model (TAM) was adopted. It was chosen the most recent version: TAM 3. TAM 3 allow to evaluate the systems features (INTCare and ENR) and their importance to ICU. To complete this process a detailed questionnaire was developed. This questionnaire was applied using the Delphi Methodology and it is based in the Technology Acceptance Methodology (TAM)(Chooprayoon \& Fung, 2010), i.e., it is concerned with the evaluation of four aspects / constructs: perceived usefulness (PU), perceived ease of use (PEOU), behavioural intention (BI) and use behaviour (UB).

This paper is divided in eight sections. The first and second sections introduce the problem and make an overview of the concepts and work previous performed. The third section presents the improvements attained in the Intensive Care according to INTCare features. Then the fourth section introduces the PIDSS at the level of results achieved. The fifth and sixth sections are related to the TAM; the questionnaire performed and results achieved. Seventh section present the contribution made by ICU professionals during the questionnaire phase. Finally, some remarks and future work were considered.

\section{BACKGROUND}

During 2009 when this project started the ICU information system was composed by a set of information silos. The ICU professionals need to access to more than five hospital applications to obtain important information in order to make their decisions. Now with the introduction of INTCare they have the most important information available in the Electronic Nursing Record (ENR) and they can obtain new knowledge automatically and in real-time moments after the patient documentation. This situation only was possible with the modification made by INTCare project and the introduction of new knowledge into the ICU DMP. 


\section{INTCARE}

INTCare (Gago et al., 2006; Santos et al., 2011) is an IDSS to predict organ failure and patient outcome for the next 24 hours in real-time using online learning. This system is result of a research project. The research and modifications done allowed to obtain new types of data in an electronically format and in real-time (Portela et al., 2011; Portela et al., 2010). The new reality and the new environment created (Portela, Santos, Silva, Machado, \& Abelha, 2011) allow for obtaining new knowledge fundamental to the decision process automatically and in real-time:

- Predict patient condition,

- Calculate the ICU scores,

- Track critical events.

The data is obtained through a streaming process and the knowledge attained is disseminated in situated devices. The data are essentially provided by the ENR. ENR allow to record, consult and validate many patient clinical data, for example: vital signs, therapeutic plans, medical scores, medical scales and others. At same time many of the data are collected and processed automatically and in real-time.

\section{DECISION MAKING PROCESS IN INTENSIVE CARE UNITS}

Making decisions in ICU is a complicated and danger process, because all tasks need to be performed quickly and accurately (Baggs, et al., 2007). The ICU professionals deal with patients in serious life-risk. The use of technologies to support this type of process is welcome (Mador \& Shaw, 2009) however, normally this type of systems aren't helping, i.e., don't present the accurate information in the right time and in the right place. These types of situations complicate the decision process. At the same time, there is a problem associated to the patient documentation because it is always relegated to a second place. In order to overcome this situation some modifications were made in the ICU environment (Portela, Santos, et al., 2011) and in the DMP. All the patient data essential to DMP are available in the ENR.

\section{TECHNOLOGY ACCEPTANCE METHODOLOGY AND DELPHI METHODOLOGY}

The evaluation of a technology application is crucial to comprehend its suitability in a specific environment and also to measure the satisfaction level of its users. One of the most used models in this area is the Technology Acceptance Methodology. "TAM is adapted from the Theory of Reasoned Action (TRA) model which describes human behaviours in a specific situation" (Fishbein \& Ajzen, 1975). The main purpose of TAM is to present an approach to study the effects of external variables towards people's internal beliefs, attitudes, and intentions (Chooprayoon \& Fung, 2010). This model is also important because it gives an understanding about the acceptance of the decision support by the ICU staff and how can be useful in the course of their daily work. The goals of TAM can be achieved by using methodologies based on questionnaires.

As a support tool it is important to use some aspects/characteristic of the Delphi method. The principles of the Delphi method involves the use of questionnaires being one of its key features (Zackiewicz \& Salles Filho, 2010) the preservation of anonymity of the participants. A questionnaire was prepared by a coordination team, composed by professionals of ICU and Information System, and sent to a set of participants (a group of experts from the ICU nurses team).

The questionnaire was prepared taking into account the constructs of TAM (Venkatesh \& Bala, 2008; Venkatesh \& Davis, 2000). The correlations of the answers were evaluated through the Kendall's tau $(\tau)$ coefficient. Kendall's tau is a measure of rank correlation. The values range from -1 (inversion) to +1 (perfect agreement). A value of zero indicates the absence of association 


\section{RELATED WORK - RESULTS OBTAINED IN THE FIRST APPROACH}

In order to make a first assessment of the technology, a quick and short questionnaire was produced (M. F. S. Filipe Portela, José Machado, António Abelha, José Neves, Álvaro Silva, Fernando Rua, 2012). The main goal was to have a first idea about the usefulness and ease of use of the system in superficial way. This questionnaire was the starting point of the second questionnaire (with tam) and it had a short scope. The questions were divided into two groups: Functional characteristics (data registration, information access and proactive performance) and Technical characteristics (efficient consulting, response time, system security, usability, and interoperability). Finally, a last question evaluate if the system suits the needs. The questionnaire was answered using a five-scale metric: Does not meet / in complete disagreement ( $<20 \%$ of cases) (1) until fully meet / fully agree (> 80\%) (5) (M. F. S. Filipe Portela, José Machado, António Abelha, José Neves, Álvaro Silva, Fernando Rua, 2012). In terms of results only two questions were answered with less than 4 points: one question about the registration system and other question about the understanding of the system and their benefits.

Concluding, in the first phase of assessment the users revealed to be comfortable with the system. These results motivated: i) to continue the development of the project; and ii) perform a more extensive and deep questionnaire having the objective to understand the technology acceptance by the ICU users.

\section{RESEARCH PROPOSE - IMPROVEMENTS INTRODUCED IN ICU}

The improvements made are according to the INTCare requirements (R1 to R6) defined in the introduction and can be summarized as:

\section{DATA ACQUISITION SYSTEM (R1)}

The first requirement was resolved with the implementation of a gateway. The gateway is connected to the vital signs monitors, reads the patient information and stores it on a database through the data acquisition agent. This is an autonomous process and it is always in a continuous collecting process (streaming).

In this phase two problems appear: missing patient identification (PID) and the acquisition of bad values. To overcome these problems two triggers were developed. One trigger to verify on the Electronic Health Record (EHR) system the PID of the patient admitted in bed where the values are provided and other trigger to validate the values. This second process uses the range of values pre-defined by ICU. Both the procedures are executed in the moment of the values are collected.

\section{LABORATORY (R2)}

Regarding to the laboratory, an effort was made to have the lab results in an open format, i.e., accessible electronically and able to be handled without restrictions. The main objective was making the results available for ICU immediately after the patient exams are concluded. This change gives the possibility to have the results in a comparative format during the patient stay in ICU. Those exams have different types and are executed by different services and at different hours (M. F. S. Filipe Portela, José Machado, António Abelha, José Neves, Álvaro Silva, Fernando Rua, 2012).

\section{OPEN ACCESS TO PRESCRIPTIONS (R3)}

In this point the objective was deal with pharmacy and to study the possibility to construct an easy access to patient prescriptions. These prescriptions were totally controlled by pharmacy and whenever someone needed to consult the patient therapeutic plan had to open a too slow platform. Now, the interaction between the pharmaceutical system and ENR is made by an agent. Periodically, the ENR agent sends a request to the pharmacy drugs system and then, the 
requested data is sent to a database table (M. F. S. Filipe Portela, José Machado, António Abelha, José Neves, Álvaro Silva, Fernando Rua, 2012).

\section{ELECTRONIC NURSING RECORD (R4 AND R5)}

Electronic Nursing Record (ENR) is a platform that it was developed with the objective to receive all medical data and put it available electronically and in real-time to the physicians and nurses in an hourly mode. ENR can achieve two requirements because being it electronic can dematerialize the processes and due the interoperability mode can interoperate with all of others ICU data sources. Currently the ICU staff using the ENR has more vital information about the patient in order to help to make their decisions. ENR is a touch and web-based platform and it is composed by different screens. The data is grouped by the information provenance.

\section{AUTOMATIC DATA PROCESSING AND TRANSFORMATION (R6)}

After obtain all the essential data to the decision making process it was necessary introduce new features to the transformation process. The uses of intelligent agents allowed automate the whole process. Now the tasks associated to data preparation process are performed automatically and in real-time without human effort. These changes increase the speed in getting new knowledge being they useful and available in the right time, i.e., in the moment of the decision is taken.

\section{PERVASIVE INTELLIGENT DECISION SUPPORT SYSTEM}

A pervasive intelligent Decision Support System (PIDSS) is recognized as a system that helps the decision making process and it is accessible anywhere and anytime. In the health care arena there are two concepts related to PIDSS as is the pervasive healthcare and the pervasive computing (Varshney, 2009). Due their pervasive features, INTCare can produce three different types of knowledge. This knowledge is available anywhere and anytime.

\section{ICU MEDICAL SCORES}

The objective of PIDSS component is to behave as an Intelligent Scoring System (ISS). The ISS (Portela, et al., 2012) is incorporated into the Electronic Nursing Record (ENR). Nowadays, the ICU professionals can record and consult the scores in real-time. This application allows for the automatic calculation in real-time of a set of scores: simplified acute physiology score (SAPS) II (Le Gall, Lemeshow, \& Saulnier, 1993), SAPSIII (Metnitz et al., 2005), Sequential Organ Failure Assessment score (SOFA) (Vincent et al., 1998), Glasgow Coma Score (GSC) (Jones, 1979), Therapeutic Intervention Scoring System (TISS-28) (Reis Miranda, de Rijk, \& Schaufeli, 1996) and Modified Early Warning Score (MEWS) (GardnerThorpe, Love, Wrightson, Walsh, \& Keeling, 2006). At the same time it is possible to analyze the patient evolution in terms of the scores through interactive graphs (in a hourly and daily base). As mentioned before (Portela, et al., 2012): this approach makes possible to provide a set of scores calculated / updated in real time. The ISS proposed processes automatically the scores and adapts the results according to the new values collected generating new knowledge. The main gains in using this approach can be summarized as:

-The data acquisition, scores calculation and results are made in real-time;

- All values are considered - no missing values;

-The data is displayed in a new way - real-time charts to compare trends;

-Less human intervention in the scores calculation - less errors;

- The scores are available anywhere and anytime;

- Help decision making process through a continuous scores monitoring. 
Critical Events (CE) are very important to the development of Data Mining (DM) models. In order to develop DM models in a real setting it was necessary to define procedures to automatically compute CE for five variables: Urine Output (Diuresis), Blood Pressure, Heart Rate, Respiratory and Temperature (P. G. Filipe Portela, Manuel Filipe Santos, Álvaro Silva, Fernando Rua, 2012). The procedure calculates according some rules the number and elapsed time of an event. Then, the value is characterized as critical or not. As result it is possible determine a number of critical events for the patient by hour and category (P. G. Filipe Portela, Manuel Filipe Santos, Álvaro Silva, Fernando Rua, 2012). In complement it is calculated the Accumulated Critical Events (ACE) (P. G. Filipe Portela, Manuel Filipe Santos, Álvaro Silva, Fernando Rua, 2012). The CE system is composed by a grid and a system similar to a traffic light. This system is used as a way to alert about the patient condition. The grid shows: the number of critical events by hour, the number of ACE, the time in critical event by hour and the total time in critical event. The implementation of this new approach allows to the physicians have better understanding of the patient's condition.

\section{ENSEMBLE BASED MODELS}

Data Mining (DM) is the centre of the PIDSS. The objective of DM system is to predict the patient organ failure (cardiovascular, hepatic, coagulation, respiratory and renal) and patient outcome for the next hour. To achieve this goal an ensemble DM was developed. To evaluate the ensemble three measures were considered: Sensibility, Accuracy and Terror. For each measure the average of 10 runs was taken. The selected models are used only if they satisfy the following conditions (quality measure): Total Error $<=40 \%$; sensitivity $>=85 \%$ and Accuracy $>=60 \%$. The use of ensemble helps to choose the best model in the cases where more than one model presents good results. From the six targets, only three satisfy the quality measures defined: outcome, cardiovascular and coagulation. The low level of results verified in the other targets it is associated to the dynamic characteristics of the environment. Currently, it is possible induce DM models in real-time using online-learning and an ensemble approach in order to adapt the predictive models automatically. The doctors can use the predictions to save lives and avoid complicated situations to the patient.

\section{TECHNOLOGY ACCEPTANCE QUESTIONNAIRES}

For this study it was elaborated a questionnaire based on the four constructs of TAM 3. This questionnaire was elaborated by taking into account some scientific articles that report similar processes of technological implementation and are framed in the hospital environment and the first results obtained. It means they were aggregated into several groups to represent all the aspects of TAM. The main purpose is to obtain a better understanding about the user's intentions on the use of this system in the long run as well as the functionality for them. The questionnaire is composed by 91 valid questions. In this questionnaire was applied the Likert Scale (Johns, 2010) to evaluate the results. This scale was chosen because the use of short scales (scales that goes between three and four) can better constrain results into close type of answers such as a simple yes or no; and secondly, by applying a higher scale this could fall into a dispersion of results that lead the answers to inaccurate results. As a consequence the chosen scale follows a range from one to five points similar to the used in the previous work / questionnaire. It allows for giving two values for each side and at the same time finding a neutrality point (Johns, 2010). The considered levels are the following:

1) Not satisfies/in complete disagreement ( $<20 \%$ of cases);

2) Satisfies a bit/in some level of disagreement (20-40\%);

3) Satisfies/under some level of agreement (40-60\%);

4) Satisfies a lot/strongly agreement (60-80\%);

5) Satisfies completely/full agreement $(>80 \%)$.

The level of results collected from this questionnaire vary by the fact of the participant answer in a properly manner (with consciousness) or not. The answers always depend on the goodwill of each participant by answering in a balanced way to the questions of a certain group. This 
hypothesis does not verify when the participant evaluates a specific characteristic as a whole and gives the same answer to the group questions. To avoid this problem it was added to the questionnaire three screening questions to understand the level of the user's consciousness (e.g. 3+2). Table 1 crosses the 91 questions with the 4 constructs: Perceived Usefulness (PU); Perceived Ease of Use (PEOU); Behavioural Intention (BI); Use Behaviour (UB).

Table 1 - Questions of User and system Characteristics

\begin{tabular}{|c|c|c|c|c|}
\hline Question & PU & PEOU & BI & $\mathbf{U B}$ \\
\hline \multicolumn{5}{|l|}{ 1. Level of experience in technology } \\
\hline \multicolumn{5}{|l|}{ 1.1. What is your experience in technology? } \\
\hline 1.1.1. How much time you spend on the computer? & $\mathrm{X}$ & $\mathrm{X}$ & & $\mathrm{X}$ \\
\hline 1.1.1.1. Less than 2 hours/day & $\mathrm{X}$ & $\mathrm{X}$ & & $\mathrm{X}$ \\
\hline 1.1.1.2. Between 2 to 4 hours/day & $\mathrm{X}$ & $\mathrm{X}$ & & $\mathrm{X}$ \\
\hline 1.1.1.3. More 4 hours/day & $\mathrm{X}$ & $\mathrm{X}$ & & $\mathrm{X}$ \\
\hline \multicolumn{5}{|l|}{ 1.2. Type of User? } \\
\hline 1.2.1. Full autonomy & $\mathrm{X}$ & & & $\mathrm{X}$ \\
\hline 1.2.2. Rarely need technical support (less than 3 times/month) & $\mathrm{X}$ & & & $\mathrm{X}$ \\
\hline 1.2.3. Need regular technical support & $\mathrm{X}$ & & & $\mathrm{X}$ \\
\hline \multicolumn{5}{|l|}{ 1.3. Use computer preferably for? } \\
\hline 1.3.1. Application of production stuff (email, word processing, spread sheet) & $\mathrm{X}$ & $\mathrm{X}$ & $\mathrm{X}$ & $\mathrm{X}$ \\
\hline 1.3.2. Handling/Consulting administrative information & $\mathrm{X}$ & $\mathrm{X}$ & $\mathrm{X}$ & $\mathrm{X}$ \\
\hline 1.3.3. Handling/Consulting clinical information & $\mathrm{X}$ & $\mathrm{X}$ & $\mathrm{X}$ & $\mathrm{X}$ \\
\hline 1.3.4. Handling/Consult management information & $\mathrm{X}$ & $\mathrm{X}$ & $\mathrm{X}$ & $\mathrm{X}$ \\
\hline \multicolumn{5}{|l|}{ 2. System INTCare } \\
\hline \multicolumn{5}{|l|}{ 2.1. Functional Characteristics } \\
\hline 2.1.1. It allows the efficient registration of the information? & & $\mathrm{X}$ & & $\mathrm{X}$ \\
\hline 2.1.2. It allows obtaining efficient information for decision support? & & $\mathrm{X}$ & & $\mathrm{X}$ \\
\hline 2.1.3. It is easy to operate? & & $\mathrm{X}$ & & $\mathrm{X}$ \\
\hline 2.1.4. It shows the prevision of Adverse Effects in an efficacy way? & & $\mathrm{X}$ & $\mathrm{X}$ & \\
\hline 2.1.5. It shows usefulness when predicts the Scores? & & $\mathrm{X}$ & $\mathrm{X}$ & \\
\hline 2.1.6. It improves the proactive performance of the professionals? & $\mathrm{X}$ & $\mathrm{X}$ & $\mathrm{X}$ & $\mathrm{X}$ \\
\hline 2.1.7. It allows tasks to be performed with greater precision? & $\mathrm{X}$ & $\mathrm{X}$ & & \\
\hline \multicolumn{5}{|l|}{ 2.1.8. Three + Two? } \\
\hline 2.1.9. Can help to mitigate situations of an excessive workload? & $\mathrm{X}$ & $\mathrm{X}$ & $\mathrm{X}$ & $\mathrm{X}$ \\
\hline 2.1.10. Can allow a major control of several tasks? & $\mathrm{X}$ & $\mathrm{X}$ & & $\mathrm{X}$ \\
\hline 2.1.11. Can help to have a better decision making based in best evidences? & $\mathrm{X}$ & $\mathrm{X}$ & $\mathrm{X}$ & $\mathrm{X}$ \\
\hline 2.1.12. Potentiates an improvement delivery of patient's health care? & $\mathrm{X}$ & $\mathrm{X}$ & & $\mathrm{X}$ \\
\hline 2.1.13. It allows inquire and modify records from the previous day? & $\mathrm{X}$ & $\mathrm{X}$ & & $\mathrm{X}$ \\
\hline 2.1.14. It allows monitoring the patient's condition? & $\mathrm{X}$ & $\mathrm{X}$ & & $\mathrm{X}$ \\
\hline 2.1.15. It promotes automating tasks? & $\mathrm{X}$ & $\mathrm{X}$ & & $\mathrm{X}$ \\
\hline 2.1.16. It allows inquire the therapeutic plan for the next day? & $\mathrm{X}$ & $\mathrm{X}$ & & $\mathrm{X}$ \\
\hline 2.1.17. It allows answering with the appropriate information to perform the task? & $\mathrm{X}$ & $\mathrm{X}$ & $\mathrm{X}$ & $\mathrm{X}$ \\
\hline \multicolumn{5}{|l|}{ 2.2. Technical Characteristics: } \\
\hline 2.2.1. Can promote quality of the information? & $\mathrm{X}$ & & $\mathrm{X}$ & $\mathrm{X}$ \\
\hline 2.2.2. Can access to information quickly? & $\mathrm{X}$ & & & $\mathrm{X}$ \\
\hline
\end{tabular}




\begin{tabular}{|c|c|c|c|c|c|}
\hline 2.2.3.1 & It allows access to information in a secure way (eg. EHR)? & $X$ & $\mathrm{X}$ & & $X$ \\
\hline 2.2.4. & Can operate simultaneously with other hospital systems? & $\mathrm{X}$ & $\mathrm{X}$ & $X$ & $\mathrm{X}$ \\
\hline 2.2 .5 & $\begin{array}{l}\text { Can facilitate an operation by having a tactile interface beside to patient's } \\
\text { beds? }\end{array}$ & $\mathrm{X}$ & $\mathrm{X}$ & $\mathrm{X}$ & $\mathrm{X}$ \\
\hline 2.2.6.1 & It allows an efficient use based on the available technical support? & $\mathrm{X}$ & $\mathrm{X}$ & $\mathrm{X}$ & $\mathrm{X}$ \\
\hline 2.3 . & Relevance of the INTCare system from the user's perspective: & & & & \\
\hline 2.3.1.1 & Did you receive any superior directive? & & & $X$ & $\mathrm{X}$ \\
\hline 2.3.2.1 & Do you think that other nurses should use the system as well? & & & $\mathrm{X}$ & $\mathrm{X}$ \\
\hline 2.3.3. & Other professional colleagues think that you should use the system? & & & $\mathrm{X}$ & $X$ \\
\hline 2.3.4. & $\begin{array}{l}\text { The person who assesses your performance does think that you should use } \\
\text { the system? }\end{array}$ & & & $\mathrm{X}$ & $\mathrm{X}$ \\
\hline 2.3.5. & The ICU chief board has been useful to implement the system? & & & $\mathrm{X}$ & $\mathrm{X}$ \\
\hline 2.3.6. & The CHP supports the utilization of the system? & & & $\mathrm{X}$ & $\mathrm{X}$ \\
\hline 2.3.7.1 & Do you believe the system influences your professional performance? & & & $\mathrm{X}$ & $\mathrm{X}$ \\
\hline 2.3.8.1 & It brings direct or indirect benefits to the patients? & $\mathrm{X}$ & & $\mathrm{X}$ & $\mathrm{X}$ \\
\hline 2.4 . & $\begin{array}{l}\text { Individually evaluate the registration of each parameter presented on } \\
\text { the Diary Panel }\end{array}$ & & & & \\
\hline 2.4.1.1 & Monitoring of the patient? & & $\mathrm{X}$ & & \\
\hline 2.4.2. & Transfusions of the patient? & & $\mathrm{X}$ & & \\
\hline 2.4.3.1 & Medication of the patient? & & $\mathrm{X}$ & & \\
\hline 2.4.4. & Outputs (Urine Output, faeces, Vomit) & & $\mathrm{X}$ & & \\
\hline 2.4.5.1 & Renal Replacement Therapy? & & $\mathrm{X}$ & & \\
\hline 2.4.6.1 & Invasive Ventilation? & & $\mathrm{X}$ & & \\
\hline 2.4 .7 & Spontaneous Ventilation? & & $\mathrm{X}$ & & \\
\hline 2.4.8.1 & Non-invasive Ventilation? & & $\mathrm{X}$ & & \\
\hline 2.4.9.1 & Neuropsychic levels? & & $\mathrm{X}$ & & \\
\hline 2.4.10. & Scale of Pain 1? & & $\mathrm{X}$ & & \\
\hline 2.4.11. & Scale of Pain 2? & & $\mathrm{X}$ & & \\
\hline 2.4.12. & Scale of delirium? & & $\mathrm{X}$ & & \\
\hline 2.4.13. & Sedation Scale? & & $\mathrm{X}$ & & \\
\hline 2.4.14. & One + one? & & $\mathrm{X}$ & & \\
\hline 2.4.15. & Glasgow? & & $\mathrm{X}$ & & \\
\hline 2.4.16.1 & Metabolic Control? & & $\mathrm{X}$ & & \\
\hline 2.4.17. & Others? & & $\mathrm{X}$ & & \\
\hline 2.4.18.1 & Positioning? & & $\mathrm{X}$ & & \\
\hline 2.4.19. & Quality of the record from the previous day? & $\mathrm{X}$ & $\mathrm{X}$ & & \\
\hline 2.4.20. & Quality of the record from the current day? & $\mathrm{X}$ & $\mathrm{X}$ & & \\
\hline 2.4.21. & The Balance is done correctly? & $\mathrm{X}$ & $\mathrm{X}$ & & \\
\hline 2.4.22.1 & Evaluation of Performance (speed)? & $\mathrm{X}$ & $\mathrm{X}$ & $\mathrm{X}$ & $\mathrm{X}$ \\
\hline 2.4.23. & Global Evaluation of the Diary? & $\mathrm{X}$ & $\mathrm{X}$ & $\mathrm{X}$ & $\mathrm{X}$ \\
\hline 2.5 & $\begin{array}{l}\text { Evaluate the potential of each registration presented on the Procedures } \\
\text { Panel: }\end{array}$ & & & & \\
\hline 2.5.1.1 & Procedures registration of the patient? & & $\mathrm{X}$ & & \\
\hline 2.5 .2 & Graphic Registration? & & $\mathrm{X}$ & & \\
\hline 2.5.3. & Global Evaluation of the Procedures? & $\mathrm{X}$ & $\mathrm{X}$ & $\mathrm{X}$ & $\mathrm{X}$ \\
\hline 2.6. & Evaluate the potential of each registration presented on the Analysis & & & & \\
\hline
\end{tabular}




\begin{tabular}{|c|c|c|c|c|c|}
\hline & Panel: & & & & \\
\hline 2.6.1. I & Disposition of data? & & $\mathrm{X}$ & & \\
\hline 2.6.2.I & It is easy to read? & & $\mathrm{X}$ & & \\
\hline 2.6.3. & Global Evaluation of Analysis? & $\mathrm{X}$ & $\mathrm{X}$ & $\mathrm{X}$ & $\mathrm{X}$ \\
\hline 2.7 & $\begin{array}{l}\text { Evaluate the potential of each registration presented on the Orders } \\
\text { Panel: }\end{array}$ & & & & \\
\hline 2.7.1.1 & Performed exams Registration? & & $\mathrm{X}$ & & \\
\hline 2.7.2.1 & Registration of the requested exams? & & $\mathrm{X}$ & & \\
\hline 2.7.3. $\mathrm{t}$ & Utility? & $\mathrm{X}$ & & & \\
\hline 2.7 .4$. & Quality of information? & $\mathrm{X}$ & & & \\
\hline 2.7.5. & Global evaluation of Orders? & $\mathrm{X}$ & $\mathrm{X}$ & $\mathrm{X}$ & $\mathrm{X}$ \\
\hline 2.8 & $\begin{array}{l}\text { Evaluate the potential of each registration presented on the } \\
\text { Intervention's panel: }\end{array}$ & & & & \\
\hline 2.8.1. & Can facilitate obtaining information regarding the realized interventions? & & $\mathrm{X}$ & & \\
\hline 2.8.2. & Can facilitate obtaining information regarding the therapeutic attitudes? & & $\mathrm{X}$ & & \\
\hline 2.8.3. & Graphic aspect? & & $\mathrm{X}$ & & \\
\hline 2.8.4. $\mathrm{I}$ & Registration of the work plan? & & $\mathrm{X}$ & & \\
\hline 2.8.5.7 & Two + Two? & & & & \\
\hline 2.8.6. & Utility of TISS28? & $\mathrm{X}$ & $\mathrm{X}$ & $\mathrm{X}$ & $\mathrm{X}$ \\
\hline 2.8.7. & Graphic aspect of TISS28? & $\mathrm{X}$ & $\mathrm{X}$ & $\mathrm{X}$ & $\mathrm{X}$ \\
\hline 2.8.8. & Global Evaluation of TISS28 & $\mathrm{X}$ & $\mathrm{X}$ & $\mathrm{X}$ & $\mathrm{X}$ \\
\hline 2.9 .1 & $\begin{array}{l}\text { Evaluate the potential of each registration presented on the Historic } \\
\text { Panel: }\end{array}$ & & & & \\
\hline 2.9 .1 .1 & Ease of consulting of patient's Historic? & & $\mathrm{X}$ & & \\
\hline 2.9.2. & Automatic creation of PDF? & & $\mathrm{X}$ & & \\
\hline 2.9.3. & Global Evaluation of Historic? & $\mathrm{X}$ & $\mathrm{X}$ & $\mathrm{X}$ & $\mathrm{X}$ \\
\hline 2.10 . & $\begin{array}{l}\text { Evaluate the potential of each registration presented on the Scores } \\
\text { panel: }\end{array}$ & & & & \\
\hline 2.10 .1$. & $\begin{array}{l}\text { The records made automatically, present similar values relatively to the } \\
\text { manuscripts ones? }\end{array}$ & $\mathrm{X}$ & $\mathrm{X}$ & & \\
\hline 2.10.1.1. & Utility of SOFA CHART? & $\mathrm{X}$ & $\mathrm{X}$ & $\mathrm{X}$ & $\mathrm{X}$ \\
\hline 2.10.1.2. & Utility of GLASGOW CHART? & $\mathrm{X}$ & $\mathrm{X}$ & $\mathrm{X}$ & $\mathrm{X}$ \\
\hline 2.10.1.3. & Graphic aspect is intuitive? & $\mathrm{X}$ & $\mathrm{X}$ & $\mathrm{X}$ & $\mathrm{X}$ \\
\hline 2.10 .1 .4 & $\begin{array}{l}\text { The graphics can help to a better understanding of the real patient's } \\
\text { condition? }\end{array}$ & $\mathrm{X}$ & $\mathrm{X}$ & $\mathrm{X}$ & $\mathrm{X}$ \\
\hline 2.10 .2$. & $\begin{array}{l}\text { By using the automation registration of Scores it facilitates the registration of } \\
\text { SAPS II? }\end{array}$ & $\mathrm{X}$ & & $\mathrm{X}$ & $\mathrm{X}$ \\
\hline 2.10.2.1. & SAPS III? & $\mathrm{X}$ & & $\mathrm{X}$ & $\mathrm{X}$ \\
\hline 2.10.2.2. & GLASGOW? & $\mathrm{X}$ & & $\mathrm{X}$ & $\mathrm{X}$ \\
\hline 2.10.3. & Global Evaluation of Scores? & $\mathrm{X}$ & $\mathrm{X}$ & $\mathrm{X}$ & $\mathrm{X}$ \\
\hline 2.11. 1 & $\begin{array}{l}\text { Evaluate the potential of each registration presented on the Vital Signs } \\
\text { Panel: }\end{array}$ & & & & \\
\hline 2.11.1. & Utility of Information? & $\mathrm{X}$ & $\mathrm{X}$ & $\mathrm{X}$ & \\
\hline 2.11.1.1. & Utility of consulting information (hourly, daily, continuous)? & $\mathrm{X}$ & $\mathrm{X}$ & $\mathrm{X}$ & \\
\hline 2.11.1.2. & Graphic aspect? & $\mathrm{X}$ & $X$ & $\mathrm{X}$ & \\
\hline 2.11.1.3. I & MEWS & $\mathrm{X}$ & $\mathrm{X}$ & $\mathrm{X}$ & \\
\hline 2.11.2. & Adverse events - Utility of system? & $\mathrm{X}$ & & $X$ & $\mathrm{X}$ \\
\hline
\end{tabular}




\begin{tabular}{|r|l|c|c|c|c|}
\hline 2.11.2.1. & The early warning system for Adverse Events is useful? & $\mathrm{X}$ & $\mathrm{X}$ & & $\mathrm{X}$ \\
\hline 2.11.2.2. & Graphic Aspect? & & $\mathrm{X}$ & & \\
\hline 2.11 .3$. & Global evaluation of the vital signs? & $\mathrm{X}$ & $\mathrm{X}$ & $\mathrm{X}$ & $\mathrm{X}$ \\
\hline $\mathbf{2 . 1 2}$. & It is advantageous to use this system in intensive care units? & $\mathrm{X}$ & & $\mathrm{X}$ & $\mathrm{X}$ \\
\hline $\mathbf{2 . 1 3}$. & Positive aspects of the system INTCare? & & & & \\
\hline $\mathbf{2 . 1 4}$. & Suggestions to mitigate the less positive aspects previously evaluated? & & & & \\
\hline $\mathbf{2 . 1 5}$. & Suggestions to make the system more advantageous? & & & & \\
\hline
\end{tabular}

\section{RESULTS}

After collecting answers from 14 questionnaires sent by email (35\% total number of nurses in ICU) an analysis of the results was performed. First a processing was done to avoid invalid or inconsistent answers given by the participants. Then was noticed that only one participant out of the 14 nurses answered the questionnaire in an inconsistent way for the proposed questions. This situation leaded to only consider 13 surveys. Table 2 presents the technology experience of the respondents.

Table 2 - Level of experience in Information Technology

\begin{tabular}{|l|l|r|}
\hline Question & Answer & Percentage \\
\hline What is your experience in & Less than 2 hours/day & $0 \%$ \\
technology - How much time & Between 2 to 4 hours/day & $57 \%$ \\
do you spend at the computer & More 4 hours/day & $36 \%$ \\
\hline \multirow{2}{*}{ Type of User? } & Full Autonomy & $62 \%$ \\
& Rarely need technical support (less than 3 times/month) & $38 \%$ \\
& Need regular technical support & $0 \%$ \\
\hline & Application of production staff (email, text processing, spreadsheet) & $62 \%$ \\
Uses computer preferably for? & Handling/Consulting administrative information & $31 \%$ \\
& Handling/Consulting clinical information & $77 \%$ \\
& Handling/Consult management information & $8 \%$ \\
\hline
\end{tabular}

\section{RESPONDENTS ANALYSIS}

Through a brief analysis (table 3), it appears that the average (mean) responses is around the 3 points. For the standard deviation, it is clear that there is a large dispersion or variability in regard to answers. The standard deviation closer to zero means that the interviewed has maintained a consistent response

Table 3 - Univariate Analysis Global Results 


\begin{tabular}{|c|c|c|c|c|c|c|c|c|c|c|c|c|c|}
\hline & A & B & c & D & E & $\mathrm{F}$ & $G$ & $\mathrm{H}$ & | & J & k & L & $M$ \\
\hline N & 91 & 91 & 91 & 91 & 91 & 91 & 91 & 91 & 91 & 91 & 91 & 91 & 91 \\
\hline Min & 2 & 1 & 2 & 1 & 1 & 2 & 3 & 2 & 1 & 1 & 1 & 2 & 2 \\
\hline Max & 4 & 5 & 4 & 5 & 5 & 4 & 5 & 4 & 5 & 5 & 5 & 4 & 4 \\
\hline Sumn & 303 & 325 & 228 & 304 & 339 & 292 & 324 & 317 & 327 & 316 & 270 & 331 & 347 \\
\hline Mean & 3,32967 & 3,571429 & 2,505495 & 3,340659 & 3,725275 & 3,208791 & 3,56044 & 3,483516 & 3,593407 & 3,472527 & 2,967033 & 3,637363 & 3,813187 \\
\hline Std. error & 0,05858516 & 0,1532257 & 0,05496947 & 0,09006819 & 0,09513942 & 0,0635085 & 0,07528341 & 0,05494505 & 0,1259669 & 0,1162506 & 0,08036934 & 0,05745197 & 0,04919893 \\
\hline Variance & 0,3123321 & 2,136508 & 0,2749695 & 0,7382173 & 0,8236874 & 0,367033 & 0,5157509 & 0,2747253 & 1,443956 & 1,229792 & 0,58779 & 0,3003663 & 0,2202686 \\
\hline Stand dev & 0,5588668 & 1,46168 & 0,5243753 & 0,8591958 & 0,9075723 & 0,6058325 & 0,718158 & 0,5241424 & 1,201647 & 1,10896 & 0,7666746 & 0,5480568 & 0,4693278 \\
\hline Median & 3 & 4 & 2 & 4 & 4 & 3 & 3 & 3 & 4 & 4 & 3 & 4 & 4 \\
\hline 25 prcntil & 3 & 2 & 2 & 3 & 3 & 3 & 3 & 3 & 3 & 3 & 3 & 3 & 4 \\
\hline 75 prentil & 4 & 5 & 3 & 4 & 4 & 4 & 4 & 4 & 4 & 4 & 3 & 4 & 4 \\
\hline Skewness & $-0,06908599$ & $-0,6570513$ & 0,2140829 & $-0,725368$ & $-0,7904923$ & $-0,1287136$ & 0,8876165 & $-0,1697797$ & $-0,8928575$ & $-0,4790014$ & $-0,3974322$ & $-1,190534$ & $-2,560176$ \\
\hline Kurtosis & $-0,6682557$ & $-1,051244$ & $-1,433855$ & $-0,7336838$ & 1,12947 & $-0,432014$ & $-0,5274912$ & $-1,449456$ & $-0,05033$ & $-0,2529606$ & 0,6986321 & 0,4614477 & 6,035608 \\
\hline Geom. mean & 3,281417 & 3,150109 & 2,451777 & 3,207727 & 3,577916 & 3,148824 & 3,494989 & 3,443254 & 3,299415 & 3,2425 & 2,846256 & 3,589766 & 3,776013 \\
\hline Coeff. var & 16,78445 & 40,92704 & 20,92901 & 25,71935 & 24,36256 & 18,8804 & 20,17049 & 15,04636 & 33,44034 & 31,93524 & 25,83977 & 15,06742 & 12,30802 \\
\hline
\end{tabular}

To the second analysis it was chosen nonparametric correlation coefficient Kendall's tau (Bolboaca \& Jantschi, 2006). It is often used as a statistical test to determine whether two variables can be considered statistically dependent. The correlation coefficient should deliver a range of $[-1,1]]$. If the agreement between the two assessments (respondents) is perfect, the coefficient has value (1). If the difference between the two evaluations is perfect (inverse of the other) the coefficient has value (-1). However, if the two evaluations are independent, the coefficient is approximately zero (Bolboaca \& Jantschi, 2006).

The results of the correlation coefficient Kendall's tau are shown in Table 4. Through analysis of Table 4, it can be seen that the nurse $\mathrm{L}$ presents a greater divergence of responses, since it has more values close to (-1). The nurses $\mathrm{C}$ and $\mathrm{H}$ show a good correlation responses. They have a Kendall equal to 0.87. This value represents that the answers between these two respondents were very similar. Other conclusions that can be drawn is that there aren't answers totally equal or opposite, because the analysis performed no shows absolute value of 1 or -1 .

Table 4 - Kendall's tau correlation results

\begin{tabular}{|c|c|c|c|c|c|c|c|c|c|c|c|c|c|}
\hline & A & B & c & D & E & $\mathrm{F}$ & G & $\mathrm{H}$ & 1 & J & $k$ & L & M \\
\hline A & & 0,0016085 & 0,85372 & 0,17192 & $1,1838 \mathrm{E}-08$ & 0,0069348 & 0,043103 & 0,71237 & 0,046118 & 0,39071 & 0,38203 & 0,00088595 & 0,16186 \\
\hline 旦 & 0,22469 & & 0,56504 & $1,6361 \mathrm{E}-06$ & 3,9063E-08 & $3,996 \mathrm{E}-05$ & $2,2345 E-06$ & 0,5356 & 0,00039413 & 0,066855 & 0,00069976 & 7,7841E-05 & 0,16719 \\
\hline C & $-0,013134$ & -0,040984 & & 0,59589 & 0,8657 & 0,00011844 & 0,10702 & 0,87863 & 0,22667 & 0,36589 & $4,5855 \mathrm{E}-07$ & 0,61504 & 0,00072429 \\
\hline D & 0,097306 & 0,34147 & 0,037776 & & $2,4021 \mathrm{E}-06$ & 0,062714 & 0,08931 & 0,29736 & 1,3796E-06 & $2,3973 \mathrm{E}-06$ & 0,0011615 & 0,0017178 & 0,00016521 \\
\hline$E$ & 0,40617 & 0,39142 & 0,012047 & 0,33595 & & 0,015065 & 0,54673 & 0,41433 & 8,6508E-09 & 5,2598E-08 & 0,083184 & 3,5579E-07 & 0,00018937 \\
\hline$F$ & 0,19232 & 0,2926 & $-0,27419$ & 0,13258 & 0,17315 & & 0,086374 & 0,012079 & 0,20983 & 0,090247 & 0,45149 & $2,698 \mathrm{E}-05$ & 0,33758 \\
\hline$\underline{Q}$ & $-0,14408$ & $-0,33699$ & 0,11481 & $-0,12103$ & $-0,042929$ & $-0,12215$ & & 0,26523 & 0,024479 & 0,10742 & 0,0016641 & 0,27749 & 0,098926 \\
\hline H & $-0,026261$ & 0,044126 & 0,010877 & $-0,074232$ & 0,058146 & 0,17878 & 0,07936 & & 0,16129 & 0,21489 & 0,81961 & 0,0084737 & 0,00042197 \\
\hline I & 0,14206 & 0,25244 & 0,086118 & 0,3439 & 0,40996 & 0,089326 & $-0,16024$ & 0,099777 & & 2,4164E-07 & 0,038793 & 0,0017047 & $5,746 E-06$ \\
\hline 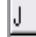 & 0,06114 & 0,13054 & 0,064407 & 0,33598 & 0,38766 & 0,12067 & 0,11468 & 0,088343 & 0,36784 & & 0,035413 & 0,00027088 & 0,00040556 \\
\hline K & 0,062268 & 0,24145 & 0,35921 & 0,23137 & 0,12341 & 0,053633 & $-0,22398$ & 0,016244 & 0,14719 & 0,14984 & & 0,63135 & 2,0398E-05 \\
\hline$L$ & 0,23681 & 0,28143 & $-0,035822$ & 0,22332 & 0,36265 & 0,299 & $-0,077356$ & 0,18752 & 0,22348 & 0,2594 & 0,034178 & & $1,4534 \mathrm{E}-05$ \\
\hline M & 0,099642 & 0,098391 & 0,24078 & 0,26833 & 0,26589 & 0,068309 & $-0,11754$ & 0,25116 & 0,32307 & 0,25191 & 0,30348 & 0,30883 & \\
\hline
\end{tabular}

For a better perception of the answers made by each interviewed, one analysis (average and mode) was carried out by questioned person and TAM construct (fig 1 to 4). In this analysis, the persons ( $\mathrm{X}$ axis) are represented by numbers (1 to 13 ).

Which it is more relevant in the first analysis (figure 1), is that the second interviewed answered most of the questions of the construct of Perceived Usefulness with 5 values, but the average is between 3 and 4 points. This means that the interviewed is quite satisfied with some aspects of the system but not with others. 


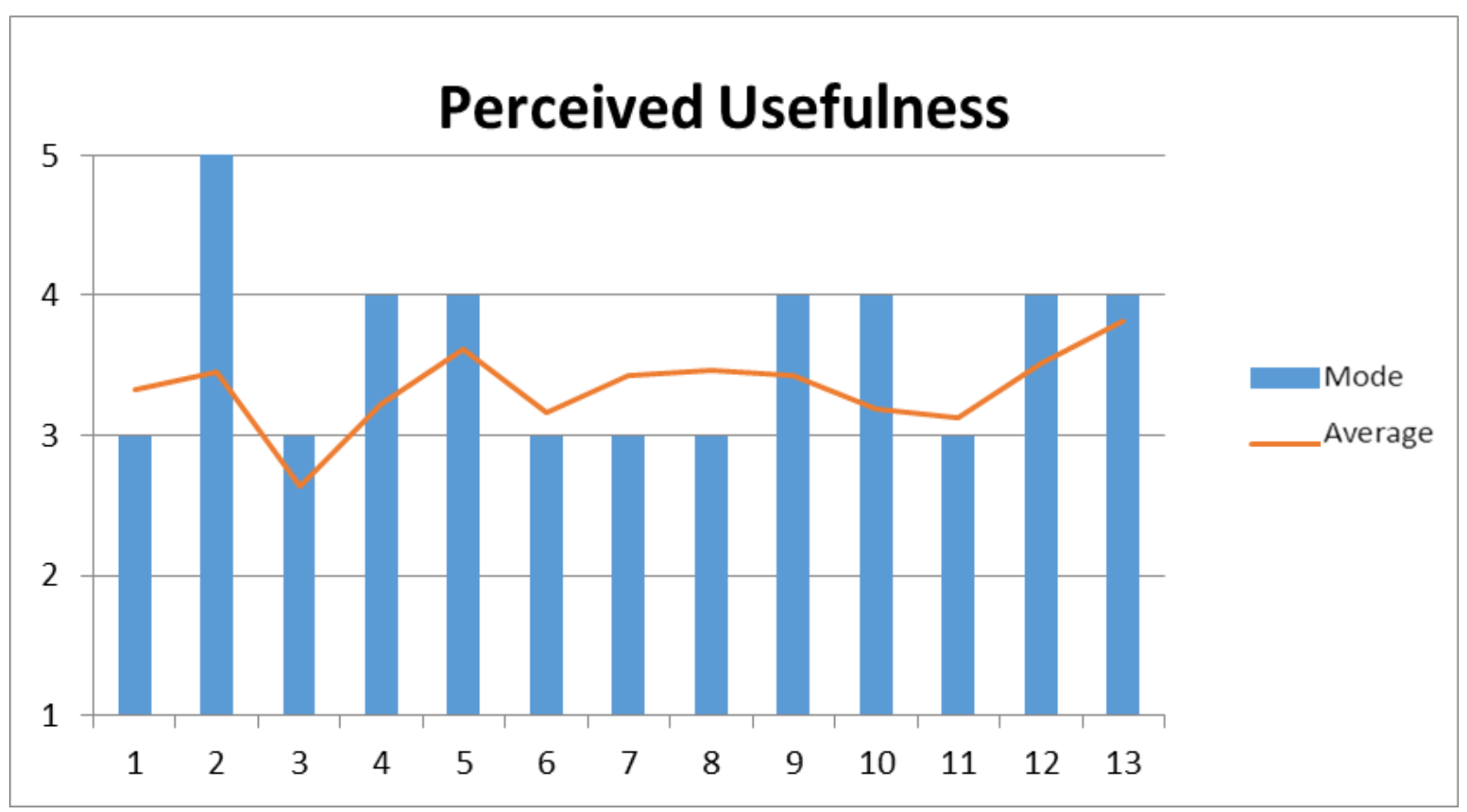

Fig 1. Evaluation of PU

In Figure 2 it is possible observes that the third interviewed answered mostly the questions with the assessment of 2 points. In contrast, the rest of the respondents in the construct of Perceived Ease of Use answered with an average between 3 and 4 points.

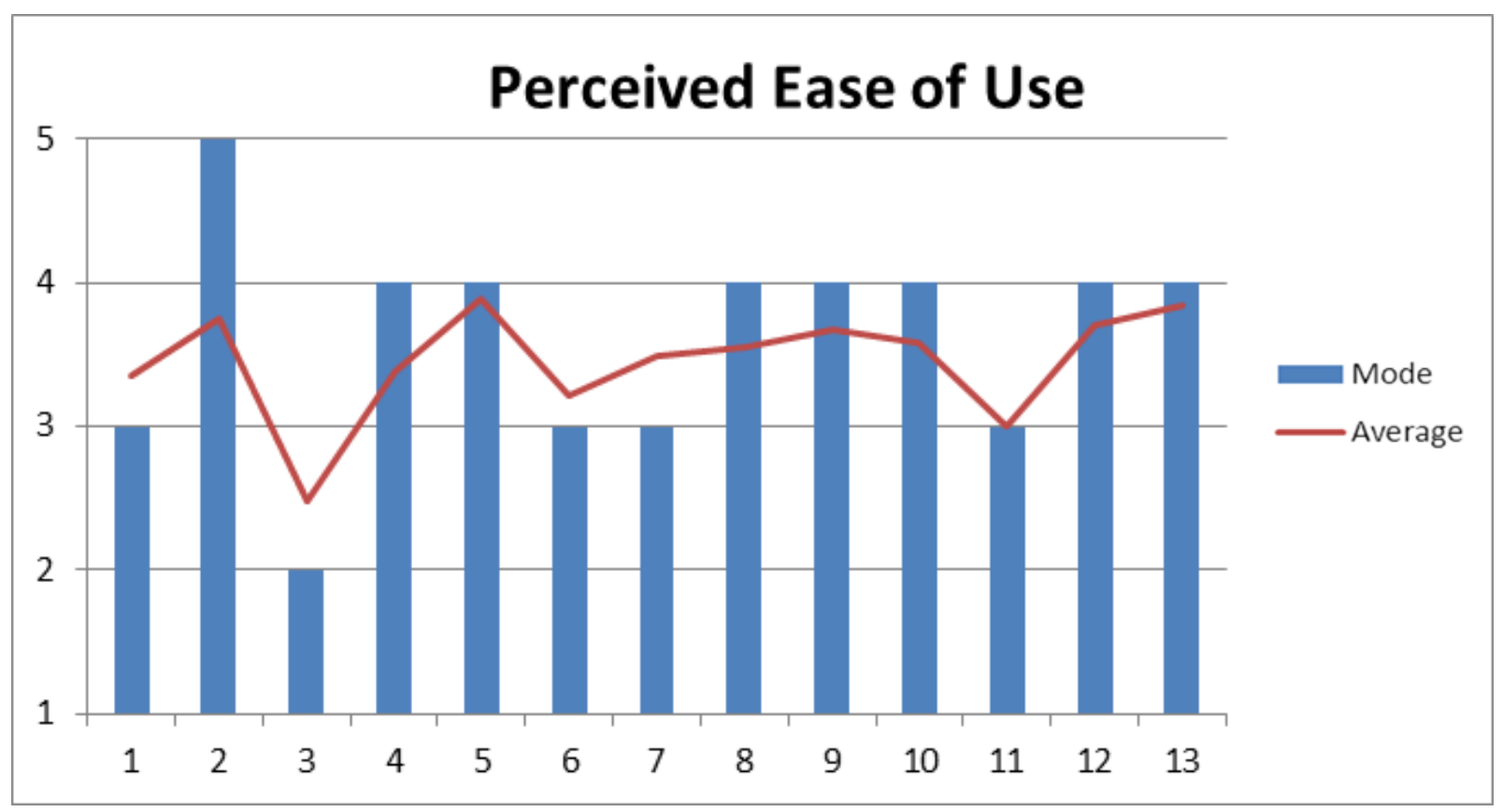

Fig 2. Evaluation of PEOU

In Figure 3, it appears that the respondents mostly answered to the question between 3 to 5 points. 


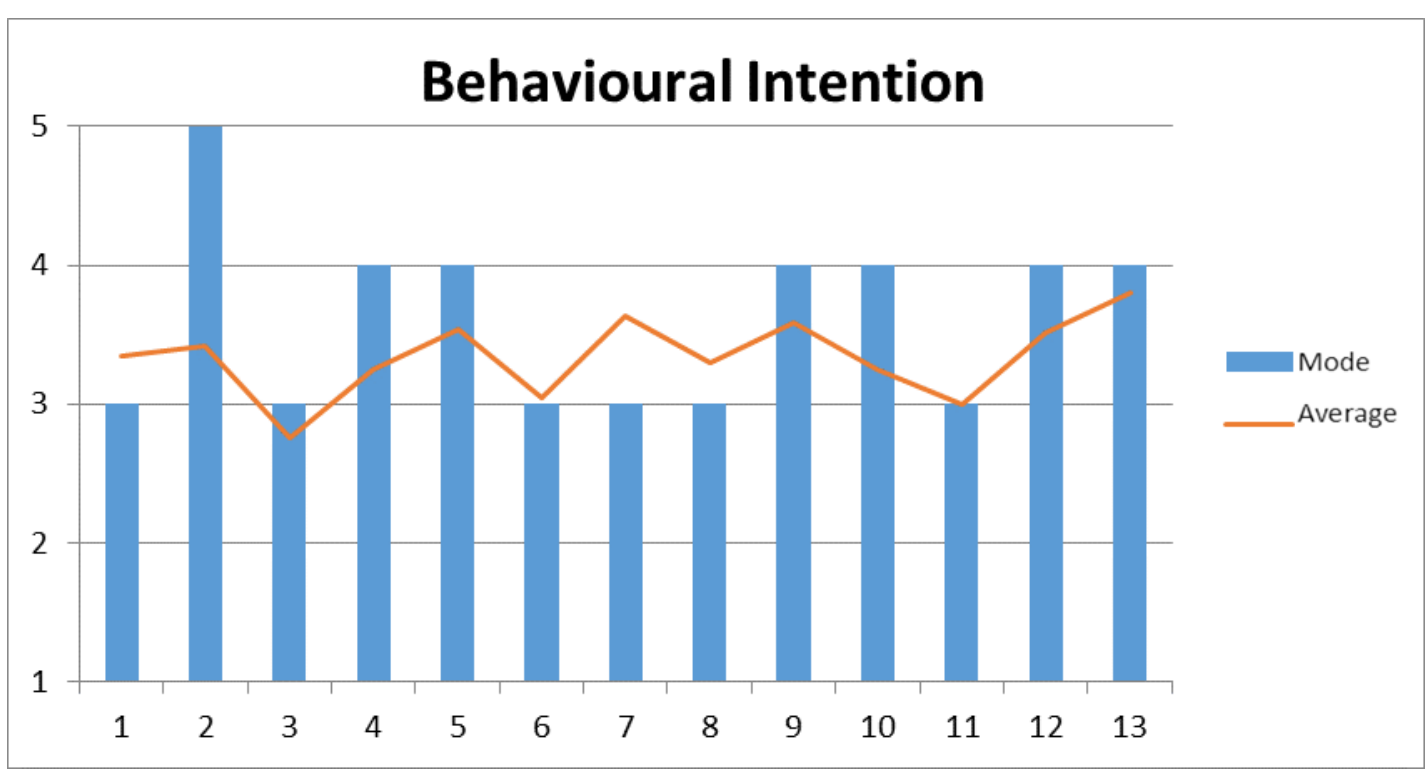

Fig 3. Evaluation of BI

In Figure 4 the responses average is somewhat lower, between 2 and 4 . The second interviewed answered this construct with a mode of 2 points, being the average near the 3 points.

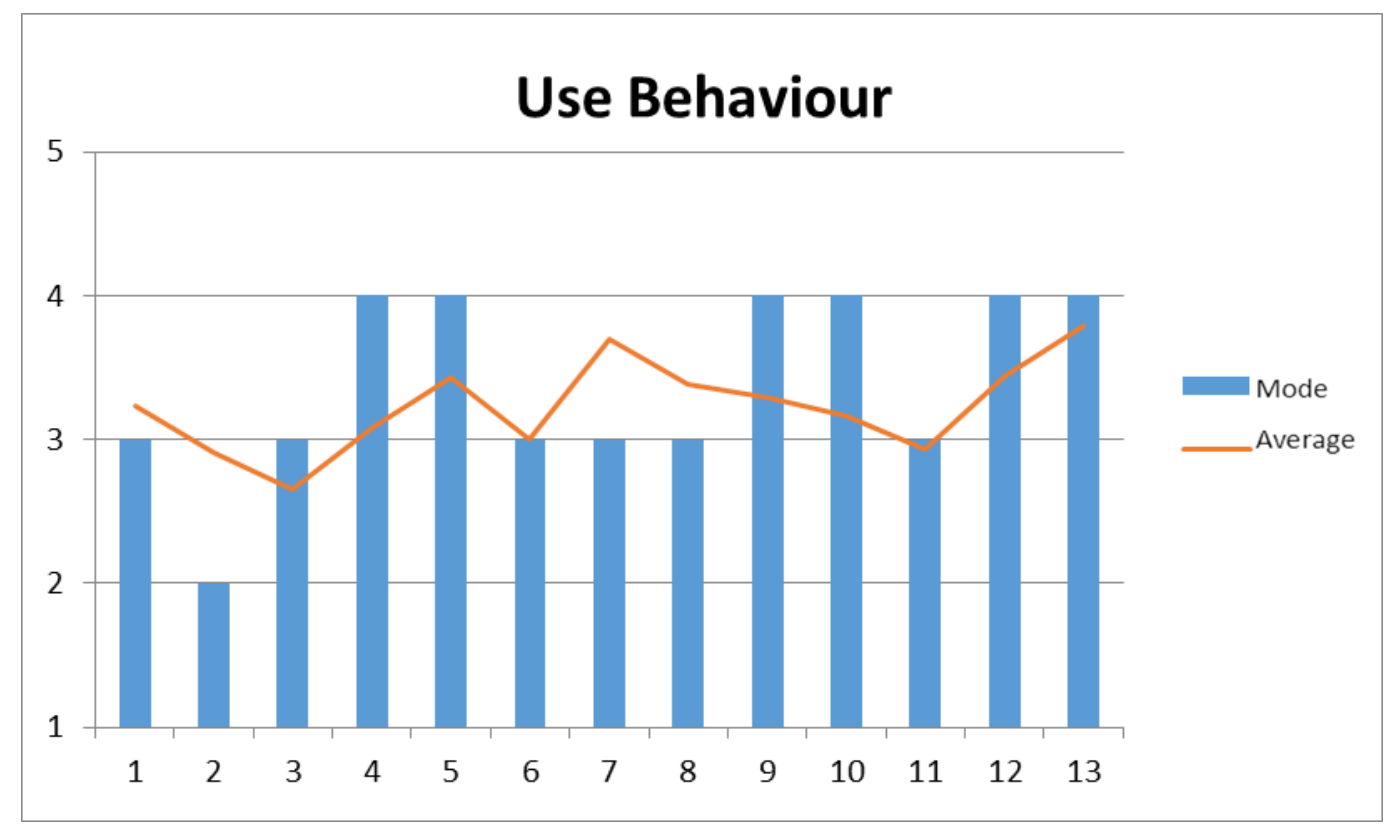

Fig 4. Evaluation of UB

At an upper level of analysis, in figures 1, 2 and 3, it is possible to observe that the second person answered most of the questions with 5 points; however the average is between 3 and 4 points. This means that this person is quite pleased with some aspects of the system and not with others. In general the evaluations are above 3 points. At same time some correlations techniques were used to understand if the users are or not in accordance with the answers. In a global analysis they are in relative accordance in some of the questions, being the overall Kendall's tau: 0,158224.

\section{QUESTION ANALYSIS}

In this sub-section, instead of doing an analysis by interviewed, was made an analysis for each 
one of the 91 questions and four constructs. In the $\mathrm{Y}$ axis are the answers of the questionnaire (1-5) and in the $X$ axis are the questions numbers. All the questions were evaluated in terms of mode and average

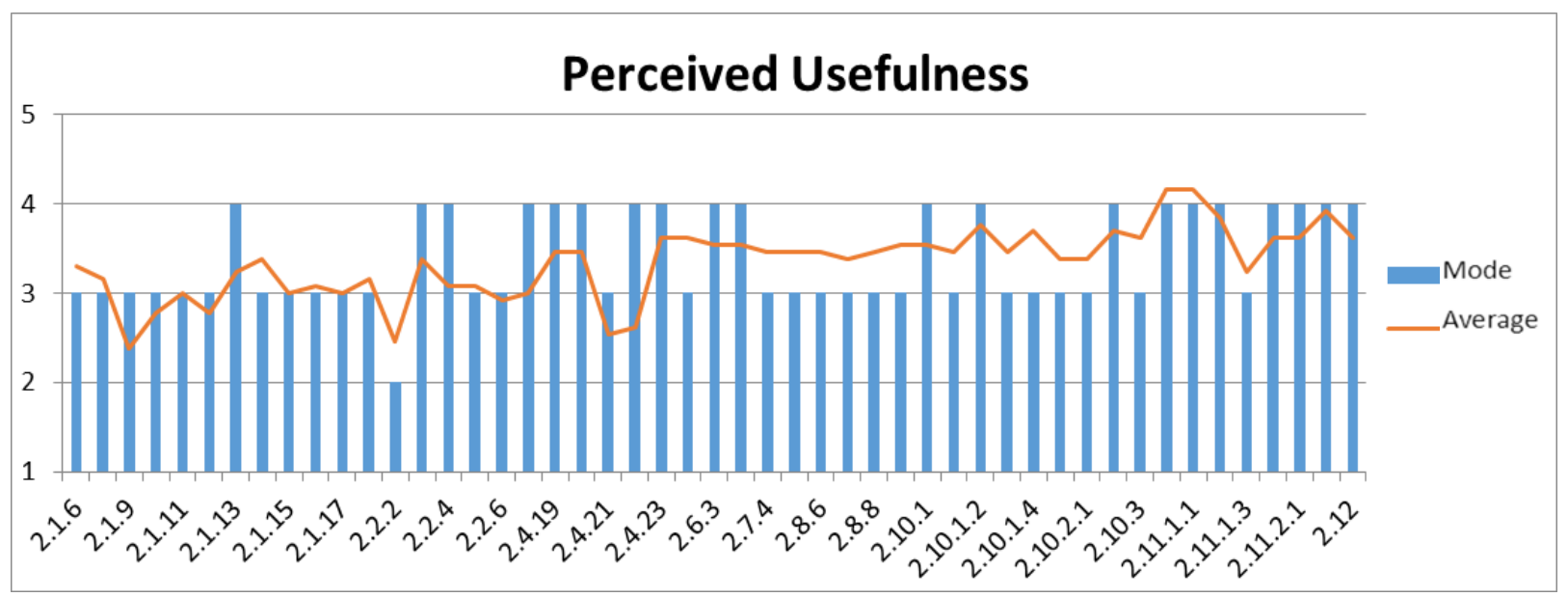

Fig 5. Analysis for questions (PU)

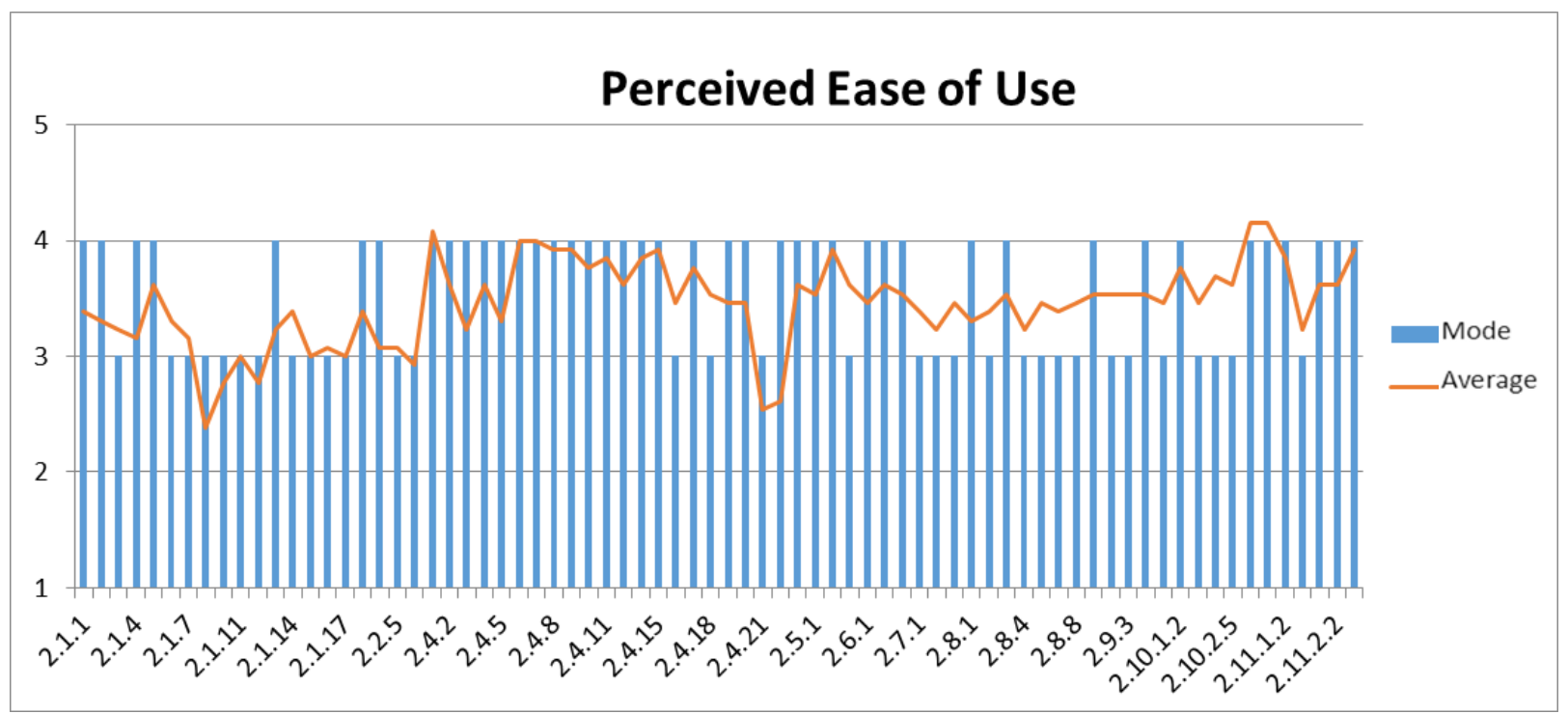

Fig 6. Analysis for questions (PEOU) 


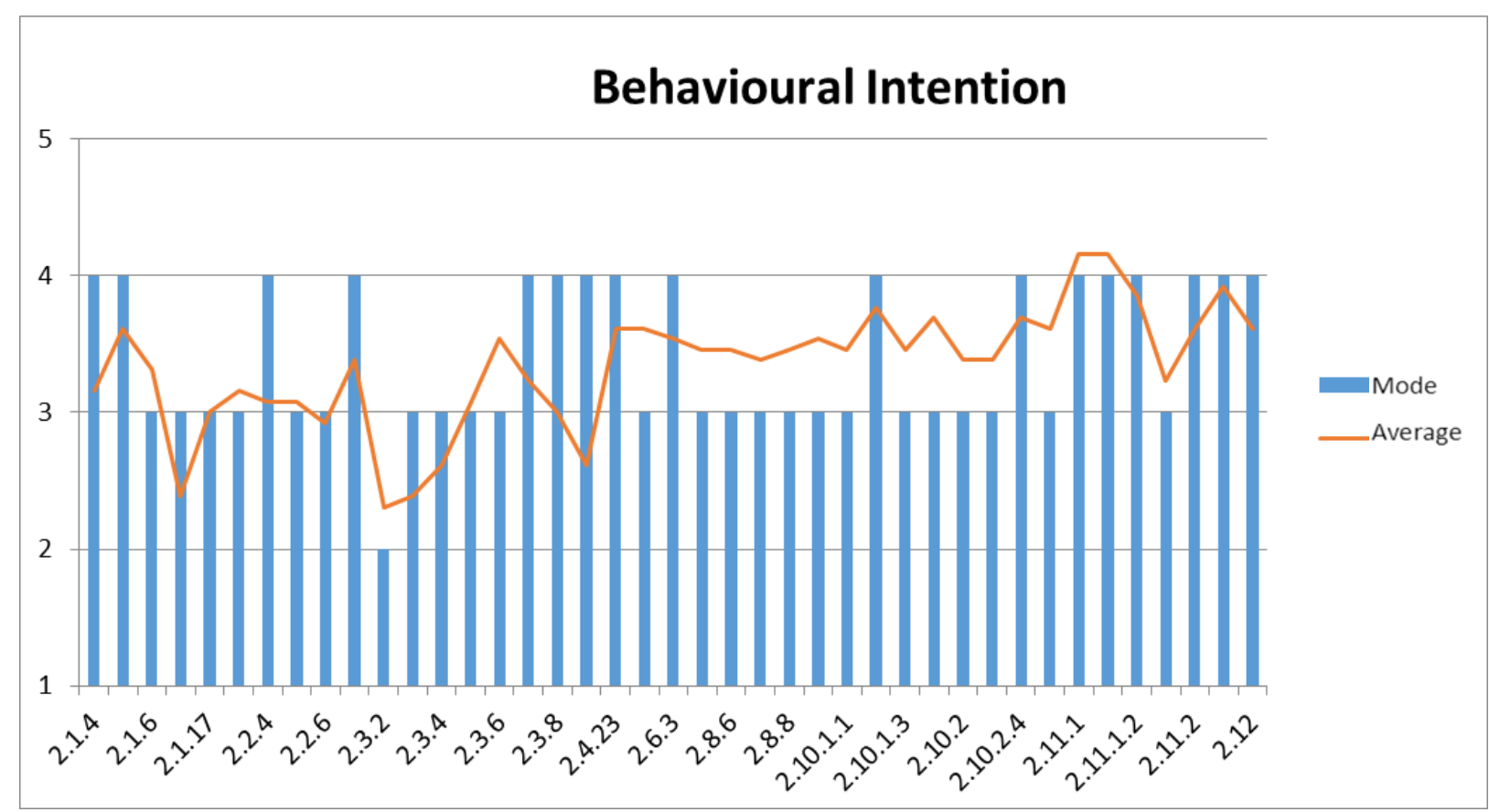

Fig 7. Analysis for questions (BI)

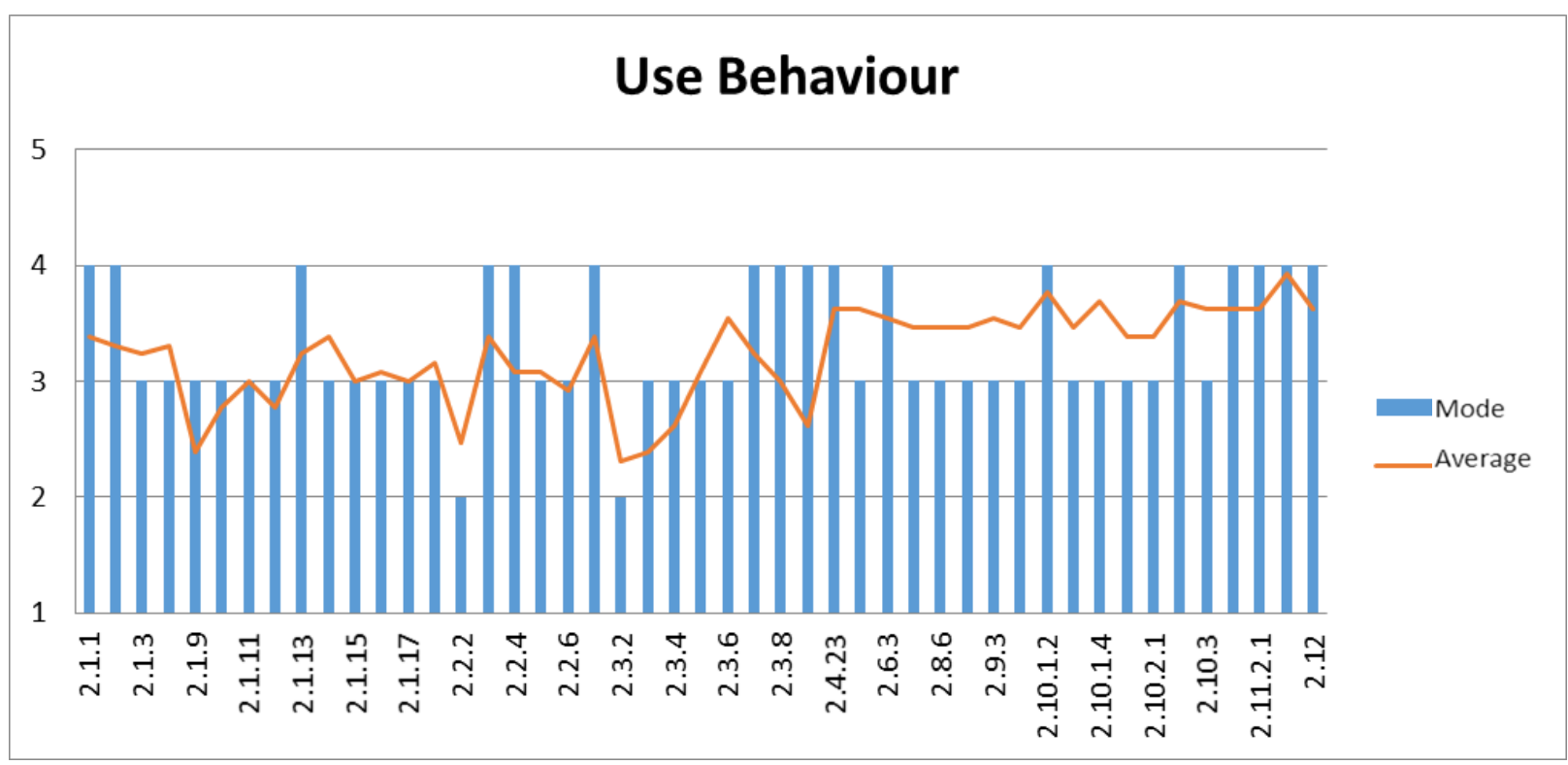

Fig 8. Analysis for questions (UB)

In figure 5, 7 and 8 it should be stressed that the questions 2.2.2 and 2.3.2 had a lowest score. On the other hand, the average of the answers for the questions related to these constructs is situated between 2 and 4 points. This result means that sometimes it is difficult to have access to the patient data in real-time because of that reason, they need to spend more time with this tasks and the nurses think that the other professionals shouldn't use the system. This happens due to hospital connectivity problems in the network. This problem represents the biggest barrier to the success of INTCare. In Figure 6, the vast majority of the answers of the questions of this constructs (PEOU) were scored with 4 points.

\section{GLOBAL ANALYSIS BY QUESTION}

A global analysis was done in order to understand the best features, the average, the mode and the standard deviation (stdev) for each one of constructs. Table 5 offers a quick view of the answers obtained by the questionnaire. This table shows that the ICU staffs are satisfied with 
the system. All the constructs present positive results being the best: the Perceived Ease of Use and the worst, the Use behaviour.

The mode were situated between three and four points. In the overall results more than $20 \%$ of questions had a classification of 4 points.

Table 5 - Summary of mode and average for each construct and analysis overall

\begin{tabular}{|l|r|r|r|r|r|}
\hline & \multicolumn{1}{|c|}{ PU } & \multicolumn{1}{|c|}{ PEOU } & \multicolumn{1}{c|}{ BI } & \multicolumn{1}{c|}{ UB } & \multicolumn{1}{c|}{ Overall } \\
\hline Mode & 3 & 4 & 3 & 3 & 4 \\
\hline Average & 3,34 & 3,45 & 3,34 & 3,23 & 3,40 \\
\hline Min & 1 & 1 & 1 & 1 & 1 \\
\hline Max & 5 & 5 & 5 & 5 & 5 \\
\hline
\end{tabular}

Table 6 offers a quick understanding of each construct. This table presents the three best and the three worst results. In the positive side they are some information (charts) to the decision process and the importance that the graphics have in order to have a better understand of the patient condition. This characteristic has as average $(a v g)$ of 4.15 . In the opposite side they are some functional characteristics. It is possible to observe that there are some negative characteristics. In general the issues are related with the system speed that consequently demotivates the system use by the professionals. Despite all that, only two question had as a mode of 2 points (2.2.2 and 2.3.2).

Table 6 - The three best and three worst questions results by TAM 3 construct

\begin{tabular}{|l|r|r|r|r|r|r|r|r|r|r|r|r|}
\hline & \multicolumn{1}{|c|}{ PU } & Mode & Avg & PEOU & Mode & Avg & BI & Mode & Avg & UB & Mode & Avg \\
\hline \multirow{3}{*}{ Best Results } & 2.11 .1 & 4 & 4,15 & 2.4 .1 & 4 & 4,08 & 2.11 .1 & 4 & 4,15 & 2.11 .3 & 4 & 3,92 \\
& 2.11 .1 .1 & 4 & 4,15 & 2.11 .1 & 4 & $4,152.11 .1 .1$ & 4 & $4,152.10 .1 .2$ & 4 & 3,77 \\
& 2.11 .3 & 4 & 3,92 & 2.11 .1 .1 & 4 & 4,15 & 2.11 .3 & 4 & $3,922.10 .2 .4$ & 3 & 3,69 \\
\hline \multirow{3}{*}{ Worst Results } & 2.1 .9 & 3 & 2,38 & 2.1 .9 & 3 & 2,38 & 2.1 .9 & 3 & 2,38 & 2.3 .2 & 3 & 2,31 \\
& 2.2 .2 & 2 & 2,46 & 2.4 .21 & 3 & 2,54 & 2.3 .2 & 2 & 2,31 & 2.1 .9 & 3 & 2,38 \\
& 2.4 .21 & 3 & 2,54 & 2.4 .22 & 4 & 2,61 & 2.3 .3 & 3 & 2,38 & 2.2 .2 & 3 & 2,46 \\
\hline
\end{tabular}

\section{CONTRIBUTIONS}

The conclusion to be drawn after the analyses made, it is that nurses are satisfied with the technology implemented in terms of innovation and functionality (Construct of Perceived Ease of Use had higher acceptance), but they complain about the real-time performance due the less responsiveness of equipment (Using Behaviour that was less accepted) used in the ICU.

After conclude the pre-defined questions, the respondents had a free text field to make opinions about the system. They made a very interesting contributions in terms of the positive aspects of the system and suggestions for mitigating the less positive aspects in order to make the system more advantageous.

\section{POSITIVE ASPECTS}

- More accurate interface (save and record options);

- Interaction with all clinical information systems (interoperability);

- At a later stage the INTCare system may be useful for the nursing staff, and ease the workload;

- Effectively gathers medical information that contributes to the decision making process, as well the nursing interventions;

- Decreases some work in relation to the registration of patient data, however requires confirmation of values. Practical record of patient's fluid balance; 
- $\quad$ Ease access to records and information of the user;

- Very intuitive;

- Computerization of records allow to have a better use of resources, greater availability of information and interconnection between different disciplines and programs.

- Allows interconnection with other systems, allows for better graphical display of the state of the patient at any given time. It includes all records attached to the patient allowing a better access to the information;

- Automatic registration of the patient's vital signs, which frees up time for other tasks.

\section{NEGATIVE ASPECTS}

- Minimized the role of nursing within the team, particularly in connection with the SAPE. Being this is a new application should include interventions / actions and the like that provide an adequate level of customer care, including language classified contemplated by SAPE;

- $\quad$ System should be faster;

- Slow processing, loss of records; need to record multiple times the same data (loss information); recording process of slow data;

- It is very slow often does not record what was previously registered;

- Need to correct the responsiveness data entry;

- The aspect graph is not inviting to use application;

- System often too slow taking adequate response to the needs of the service

\section{IMPROVE SUGGESTIONS}

- Scheme should include enteral feeding in this service, similar regimen of administration of insulin;

- Allow greater freedom to record in some fields, particularly in fields related to medication;

- Develop of a user manual;

- Improve the speed of the system;

\section{CONCLUSIONS AND FUTURE WORK}

First, it should be noted that the initial objective proposed regarding to the junction of the Technology Acceptance Model (TAM 3) with the Delphi's method can be considered a success. This combination allow to evaluate the technology acceptance by users, their perceptions and the impact on the INTCare's system usage behaviour recurring to predefined questionnaires.

This is the first approach to assess the impact of such type of solutions in ICU environment. The adoption of this solution also gave some ideas how it can be implemented, what are the main requirements and what should be done in order to evaluate some technologies in Intensive Medicine. Finally the questionnaires present some questions that should be made always some technology is implemented. The questions should be focused in the four constructs of TAM in order to evaluate not only the technical features, but also the environment, behaviours and other aspects. TAM3 also should be used in order to understand what should be improved in the ICU in terms of technologies. In this case also should be considered the inclusion of a free text field with the objective to give the opportunity to the professionals express their feelings about the experience with the technology.

In particular in this project and in order to understand the acceptance level it was possible to conclude that the ICU staff it was very comfortable with the INTCare system. They pointed the data access, data save and their derivate as the biggest problem. At same time, they present as 
the biggest gain the utility of the information generated to the decision process. The user acceptance was very positive (average upper than 3 points) for the four constructs assessed: Perceived Usefulness, Perceived Ease of Use, Behavioural Intention and Usage Behaviour. Concluding, in general the ICU professionals are receptive to new systems that can introduced in their environments and can be useful to the DMP. The case studied - INTCare system is a good example because it provides a set of new knowledge important to the DMP

The results obtained by the questionnaires allow for some concluding remarks:

$\checkmark$ These results encourage further development and optimization of the solutions designed, as well as a deeper assessment of all the resources available;

$\checkmark$ It is required an improvement of physical resources (e.g. memory, hardware) of the ICU. In the future the system should be improved and another round of questionnaires deployed.

\section{ACKNOWLEDGEMENTS}

This work is supported by FEDER through Operational Program for Competitiveness Factors - COMPETE and by national funds though FCT - Fundação para a Ciência e Tecnologia in the scope of the project: FCOMP-01-0124-FEDER-022674.

The authors would like to thank FCT (Foundation of Science and Technology, Portugal) for the financial support through the contract PTDC/EIA/72819/2006 (INTCare) and PTDC/EEISII/1302/2012 (INTCare II). The work of Filipe Portela was supported by the grant SFRH/BD/70156/2010 from FCT.

\section{REFERENCES}

Baggs, J. G., Norton, S. A., Schmitt, M. H., Dombeck, M. T., Setters, C. R., \& Quinn, J. R. (2007). Intensive care unit cultures and end-of-life decision making. [Article]. Journal of Critical Care, 22(2), 159-168.

Bolboaca, S. D., \& Jantschi, L. (2006). Pearson versus Spearman, Kendall's tau correlation analysis on structureactivity relationships of biologic active compounds. Leonardo Journal of Sciences, 5(9), 179-200.

Chooprayoon, V., \& Fung, C. C. (2010). TECTAM: An Approach to Study Technology Acceptance Model (TAM) in Gaining Knowledge on the Adoption and Use of E-Commerce/E-Business Technology among Small and Medium Enterprises in Thailand.

Filipe Portela, F. P., Manuel Filipe Santos. (2012). Data Mining Predictive Models For Pervasive Intelligent Decision Support In Intensive Care Medicine. Paper presented at the KMIS 2012 - nternational Conference on Knowledge Management and Information Sharing.

Filipe Portela, M. F. S., José Machado, António Abelha, José Neves, Álvaro Silva, Fernando Rua. (2012). Intelligent Decision Support in Intensive Care-Towards Technology Acceptance. Paper presented at the 26th European Simulation and Modelling Conference - ESM'2012.

Filipe Portela, P. G., Manuel Filipe Santos, Álvaro Silva, Fernando Rua. (2012). Intelligent and Real Time Data Acquisition and Evaluation to Determine Critical Events in Intensive Medicine. Paper presented at the HCist'2012 - International Conference on Health and Social Care Information Systems and Technologies, Portugal.

Fishbein, M., \& Ajzen, I. (1975). Belief, attitude, intention and behaviour: An introduction to theory and research: Addison-Wesley.

Gago, P., Santos, M. F., Silva, Á., Cortez, P., Neves, J., \& Gomes, L. (2006). INTCare: a knowledge discovery based intelligent decision support system for intensive care medicine. Journal of Decision Systems.

Gardner-Thorpe, J., Love, N., Wrightson, J., Walsh, S., \& Keeling, N. (2006). The value of Modified Early Warning Score (MEWS) in surgical in-patients: a prospective observational study. Annals of The Royal College of Surgeons of England, 88(6), 571.

Johns, R. (2010). Likert Items and Scales. Survey Question Bank: Methods Fact Sheet, 1.

Jones, C. (1979). Glasgow coma scale. AJN The American Journal of Nursing, 79(9), 1551.

Le Gall, J. R., Lemeshow, S., \& Saulnier, F. (1993). A new Simplified Acute Physiology Score (SAPS II) based on a European/North American multicenter study. JAMA, 270(24), 2957-2963.

Mador, R. L., \& Shaw, N. T. (2009). The impact of a Critical Care Information System (CCIS) on time spent 
charting and in direct patient care by staff in the ICU: a review of the literature. International Journal of Medical Informatics, 78(7), 435-445.

Metnitz, P. G. H., Moreno, R. P., Almeida, E., Jordan, B., Bauer, P., Campos, R. A., et al. (2005). SAPS 3 -From evaluation of the patient to evaluation of the intensive care unit. Part 1: Objectives, methods and cohort description. Intensive care medicine, 31(10), 1336-1344.

Portela, F., Gago, P., Santos, M. F., Silva, A., Rua, F., Machado, J., et al. (2011). Knowledge Discovery for Pervasive and Real-Time Intelligent Decision Support in Intensive Care Medicine. Paper presented at the KMIS 2011- International Conference on Knowledge Management and Information Sharing.

Portela, F., Santos, M., Vilas-Boas, M., Rua, F., Silva, Á., \& Neves, J. (2010). Real-time Intelligent decision support in intensive medicine. Paper presented at the KMIS 2010- International Conference on Knowledge Management and Information Sharing.

Portela, F., Santos, M. F., Machado, J., Silva, Á., Rua, F., \& Abelha, A. (2012). Intelligent Data Acquisition and Scoring System for Intensive Medicine. In Springer (Ed.), Lecture Notes in Computer Science - Information Technology in Bio- and Medical Informatics (Vol. 7451/2012, pp. 1-15). Viena, Austria.

Portela, F., Santos, M. F., Silva, Á., Machado, J., \& Abelha, A. (2011). Enabling a Pervasive approach for Intelligent Decision Support in Critical Health Care. Paper presented at the HCist 2011 - International Workshop on Health and Social Care Information Systems and Technologies.

Reis Miranda, D., de Rijk, A., \& Schaufeli, W. (1996). Simplified Therapeutic Intervention Scoring System: the TISS-28 items--results from a multicenter study. Critical care medicine, 24(1), 64.

Santos, M. F., Portela, F., Vilas-Boas, M., Machado, J., Abelha, A., \& Neves, J. (2011). INTCARE - Multi-agent approach for real-time Intelligent Decision Support in Intensive Medicine. Paper presented at the 3rd International Conference on Agents and Artificial Intelligence (ICAART), Rome, Italy.

Varshney, U. (2009). Pervasive Healthcare Computing: EMR/EHR, Wireless and Health Monitoring: SpringerVerlag New York Inc.

Venkatesh, V., \& Bala, H. (2008). Technology acceptance model 3 and a research agenda on interventions. Decision Sciences, 39(2), 273-315.

Venkatesh, V., \& Davis, F. D. (2000). A theoretical extension of the technology acceptance model: Four longitudinal field studies. Management science, 186-204.

Vincent, J., Mendonça, A., Cantraine, F., Moreno, R., Takala, J., Suter, P., et al. (1998). Use of the SOFA score to assess the incidence of organ dysfunction/failure in intensive care units : Results of a multicenter, prospective study. Critical care medicine, 26, 1793-1800.

Zackiewicz, M., \& Salles Filho, S. (2010). Technological Foresight-Um instrumento para política científica e tecnológica. Parcerias estratégicas, 6(10). 